\title{
Factors Associated with Ectopic Pregnancy at Mbarara University Teaching Hospital in South Western Uganda
}

\author{
Mpiima DP*, Lugobe H and Ssemujju A \\ Department of Obstetrics and Gynecology, Mbarara University of Science and technology, Uganda \\ *Corresponding author: Mpiima DP, Bachelor of Medicine and surgery Mbarara University of Science and technology, Uganda.
}

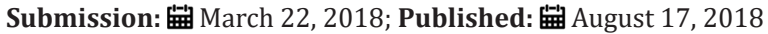

\begin{abstract}
Background: Ectopic pregnancy (EP) is a life-threatening condition and a gynecological emergency which affects one in every 80-100 pregnancies. Risk factors for ectopic pregnancy identified in previous studies include low level of education, two or more lifetime sexual partners, smoking, prior history of vaginal discharge, previous use of intrauterine contraceptive device, tubal corrective surgery, tubal sterilization, previous history of induced abortion, early age of sexual debut, inconsistent condom use, multiple sexual partners, infertility, previous pelvic or abdominal surgery and previous genital infections.
\end{abstract}

Objective: We sought to identify/determine the factors associated with ectopic pregnancy at Mbarara Regional Referral Hospital (MRRH) Gynecological ward.

Methods: This was an unmatched case-control study carried out at MRRH involving 25 cases and 76 controls. Cases were women treated for ectopic pregnancy and the controls were women with normal intrauterine pregnancies from the antenatal clinic. Information on their sociodemographic, sexual and reproductive characteristics was obtained using a semi-structured questionnaire. Serological evidence of prior chlamydial infection was determined in both groups by testing for the presence of Chlamydia immunoglobulin G antibodies in their blood. Logistic regression was used to determine the factors associated with ectopic pregnancy. The significant level of $<0.05$ was used. Odds ratios and their corresponding 95\% CIs were provided at both univariate and multivariate analysis.

Results: The factors associated with ectopic pregnancy included history of previous abdominal/pelvic surgery (aOR 6.9; CI: 1.47-32.98; $\mathrm{p}=0.000$ ) being a single woman (aOR 12.0; 2.21-65.32; $\mathrm{p}=0.0026)$ and presence of Chlamydia antibodies with Odds ratio (O.R 4.9; CI: 1.15-21.29; $\mathrm{p}=0.002$ )

Conclusion: The factors associated with ectopic pregnancy included history of previous abdominal/pelvic surgery, being a single woman and prior chlamydia trachomatis infection.

\section{Introduction}

Ectopic pregnancy refers to implantation of a fertilized egg in a location outside of the uterine cavity [1]. The most common extra-uterine location is the fallopian tube, which account for $98 \%$ of all ectopic gestations. Other sites are ovary, cervix, corn of the uterus and abdominal cavity [2]. Ectopic pregnancy (EP) is a lifethreatening condition and a gynecological emergency which affects one in every 80-100 pregnancies [3]. There is a fourfold increase in the incidence of ectopic pregnancy in the industrialized countries (from 0.3 to $1.2 \%$ ) [4]. Such rise is mainly attributed to advanced techniques for diagnosing early ectopic pregnancy and increased prevalence of pelvic inflammatory disease [5]. The incidence of EP in Africa ranges between 0.5-3\% [6,7]. Risk factors for ectopic pregnancy identified in previous studies include a strong association between prior Pelvic Inflammatory Diseases (PID) and EP with OR ranging from 2.0 to 10.1 [8]. The importance of infectious factors in ectopic pregnancy is well documented [9] There is probably a causal link. In Sweden, declining rates of Chlamydia infections, attributed to preventive policies, have been accompanied by a fall in the risk of ectopic pregnancy [10]. The other variables suggestive of a higher probability of exposure to sexually transmitted diseases (age at first intercourse and number of sexual partners) were associated with a risk of ectopic pregnancy in univariate analysis. Chlamydia trachomatis is the most common sexually bacterial infection in the world [11]. It is capable of infecting the genital organs of women and men. Generally, the infection does not produce symptoms or can produce mild symptoms [12].

Reinfection occurs easily if the partners do not receive treatment. Chlamydia prevalence and incidence is higher in individuals 16 to 19 years old [13]. Increase in the number of ectopic pregnancies is also attributed to increase in the incidence 
of pelvic infections. Chlamydia trachomatis is responsible for the most common sexually transmitted bacterial infection. In 2008, an estimated 106 million new cases of urogenital chlamydia among adults occurred globally, the largest burden being in low income countries [14]. In 2010 WHO estimated 10 million new infections of chlamydia in Africa [15]. Additionally, previous studies [16] have found that, among all the possible risk factors of EP, the strongest evidence is for an association between previous EP and sequent EP. Barnhart et al 2006 indicated that the risk of facing a repeat EP increases intensely with the number of prior EP (OR=2.98 for one prior EP and $\mathrm{OR}=16.04$ for 2 or more). Other research studies also estimated the risk of facing a repeat EP to be between 2.4 and 25.0 [17]. Furthermore, it has been reported that previous tubal surgery is a major risk factor for EP with an estimated OR of 4.7 (2.4-9.5) according to a meta-analysis. It is uncertain whether the increased risk is arising from a surgical procedure or from the underlying problem. Also, previous studies have reported different results about the association between non-tubal abdominal or pelvic surgery and subsequent EP from no association to OR ranging from 2.4 to 5.0 [18]. Previous studies found that the risk of EP increases with advancing maternal age [9]. Based on some results, the average maternal age was significantly higher for women with EP than controls. Furthermore, compared with women aged $\leq 26$ years, the risk of EP for women aged 27-32 and aged 33-38 were 3.9 and 4.3 times higher respectively, while women aged $\geq 39$ years approximately had a 9-fold risk of EP [19]. Existing evidence on how advanced maternal age has an effect on EP risk remains unclear. It is improbable that the higher risk of EP in older age cohorts is due to chromosomal abnormalities in the trophoblastic tissue [9]. Some researchers attributed it to some age-related factors, such as: Possible tubal scarring from PID, major gonococcal and chlamydial epidemics and changes in tubal function leading to delay in ovum transport and tubal implantation [20]. However, these hypotheses need to be investigated.

Several studies have reported a strong association between tobacco use and EP. In a meta-analysis, smoking patients demonstrated significantly higher odds of EP (OR=15.69, 95\% CI2.87-85.76). Studies have also found that there is an association between spouse's cigarette smoking and EP with an OR of 1.7 (95\% CI: 1.05-2.85). [21,22]. Although, the reason why smoking causes EP remains unknown, animals studies have shown that inhalation of cigarette smoke may impair fallopian tube function by affecting ciliary beat frequency and smooth muscle contraction [19]. Early studies on risk factors of EP indicated that OR greater than one belonged to current IUD use [21]. Although the exact mechanism by which implantation is occurring outside the uterus is not well understood, it is thought that IUD-induced inflammation may result in deciliation of the endosalpinx and this delays ovum transport, which leads to EP [23]. In a case-control study comparing 243 women using an IUD and suffering from EP to 140 IUD users with an intrauterine pregnancy, studies have also described that progesterone IUD, duration of IUD use, and pelvic pain after the insertion of the IUD are the factors increasing the risk of EP in IUD users. In addition, other influencing factors associated with decreasing risk of EP are the displacement of the IUD and use of anti-inflammatory drugs before the pregnancy.

The results concerning EP after spontaneous abortion differ among studies. Spontaneous abortions may have a causal effect, possibly mediated by infection. However, there may also be common risk factors for ectopic pregnancy and spontaneous abortions, such as chromosomal abnormalities or hormonal factor [23]. The available evidence suggests that the chromosomal abnormalities may be ruled out, but hormonal factors require further study, together with other factors including immunologic factors. Multiple studies have produced conflicting results regarding the association between EP and a history of induced abortions [9]. However, a large case-control study including 803 cases of EP showed an increased risk of EP for women with a history of two or more prior induced abortion with an adjusted OR of 1.9 (95\% CI=1.0-3.8) [16]. Therefore, our study sought to identify and determine the factors associated with ectopic pregnancy at Mbarara University Teaching Hospital in Southwestern Uganda.

\section{Materials and Methods}

This was an unmatched case-control study i.e. (1:3 ratio of cases to controls) carried out at Mbarara Regional Referral Hospital between September 2016 to January 2017. Consecutive sampling method was used to enrol all mothers who met the inclusion criteria until the sample size was achieved.The cases were 25 consecutive women with a diagnosis of ectopic pregnancy during the study period. The control group was made up of women with confirmed uncomplicated intrauterine pregnancy, attending the antenatal clinic of MRRH. Each case of ectopic pregnancy was followed by pregnant controls attending the antenatal clinic. The sample size for this study was calculated using the Kelsey et al (1996) formula for calculating sample size for unmatched casecontrol studies. After computing for the expected $10 \%$ attrition, the sample size was calculated to be 25 cases and 76 controls giving a total sample size of 101 . All patients who had laparotomy for tubal ectopic pregnancy, who consented to this study and satisfied the inclusion and exclusion criteria, were recruited until the minimum sample size was obtained. The approval to conduct the study was obtained from the Department of Obstetrics and Gynecology, Faculty of Medicine Research Committee (DMS 6), MUST Research Ethics Committee (No. 21/7-16) and the Uganda National Council of Science and Technology (HS 2146). Informed consent was obtained from all respondents and confidentiality was ensured. Study participants were identified by study codes and not their names, for issues of confidentiality. In addition, authority was sought from the office of the hospital director of MRRH to conduct the study in this institution.

\section{Results}

Majority of the participants were Banyankole, had at least primary level of education and were residents of Mbarara. Mean age of the cases was $27.8 \pm 4.3$ and $25.2 \pm 5.9$ for controls. There were significantly more [12(48.0\%)] single women among the cases population with ectopic pregnancy than the controls 
[5(6.58\%)] $[\mathrm{p}<0.01]$. (Table1). Table 2 shows sexual behaviour of the participants. The cases engaged in sexual intercourse at a significantly younger age than the controls $(p<0.01)$. There were more cases participants with multiple sexual partners compared to the control group. Previous history of pelvic inflammatory disease was obtained in $24(96.00 \%)$ among the cases. This was significantly more than $8(10.53 \%)$ among the controls $(\mathrm{p}=0.02)$. The cases group had significantly more surgeries $13(52.00 \%)$ compared to only $6(7.89 \%)$ among the control group. Table 3 shows that prior chlamydia trachomatis infection, single women and a history of previous pelvic / abdominal surgery are independently associated with ectopic pregnancy at Mbarara Regional Referral Hospital. Logistic regression model analysis of risk factors for ectopic pregnancy showed a four-fold increase in the risk of ectopic pregnancy in those with C. trachomatis antibodies when controlling for previous history of pelvic inflammatory disease (O.R 4.9; 95\% CI 1.15-21.29). Controlling for the effects of sociodemographic characteristics, previous history of pelvic inflammatory disease, marital status, number of sexual partners showed that single women (OR 12.0; 95\% CI 2.21-65.32) and having a history of previous abdominal/pelvic surgery (OR 6.9; 95\% CI 1.47-32.98) were shown to be more likely to be associated with ectopic pregnancy as well.

Table 1: Sociodemographic Characteristics ( $N=101)$

\begin{tabular}{|c|c|c|c|}
\hline Characteristic & $\begin{array}{c}\text { Controls } \\
\mathbf{n}(\%)\end{array}$ & $\begin{array}{c}\text { Cases } \\
\mathbf{n}(\%)\end{array}$ & P-value \\
\hline Age in years & & & \\
\hline $16-19$ & $12(15.79)$ & $1(4.00)$ & \\
\hline $20-24$ & $38(50.00)$ & $6(24.00)$ & \\
\hline $25-34$ & $21(27.63)$ & $14(56.00)$ & 0.011 \\
\hline $35-42$ & $5(6.58)$ & $4(16.00)$ & \\
\hline Mean age & $27.8 \pm 4.3$ & $25.2 \pm 5.9$ & \\
\hline District & & & \\
\hline Mbarara & $68(90.67)$ & $20(80.00)$ & \\
\hline
\end{tabular}

\begin{tabular}{|c|c|c|c|}
\hline Greater Bushenyi & $4(5.33)$ & $4(16.00)$ & 0.234 \\
\hline Others & $4(4.00)$ & $1(4.00)$ & \\
\hline \multicolumn{4}{|l|}{ Residence type } \\
\hline Rural & $38(50.00)$ & $13(52.00)$ & 0.862 \\
\hline Urban & $38(50.00)$ & $12(48.00)$ & \\
\hline \multicolumn{4}{|l|}{ Tribe } \\
\hline Banyankore & $59(77.63)$ & $20(80.00)$ & \\
\hline Baganda & $5(6.58)$ & $3(12.00)$ & \\
\hline Bakiga & $7(9.21)$ & $2(8.00)$ & 0.496 \\
\hline Others & $5(6.58)$ & $0(0.00)$ & \\
\hline \multicolumn{4}{|l|}{ Level of education } \\
\hline No formal education & $2(2.63)$ & $0(0.00)$ & \\
\hline Primary education & $38(50.00)$ & $6(24.00)$ & \\
\hline Secondary education & $24(31.58)$ & $11(44.00)$ & 0.075 \\
\hline Tertiary education & $12(15.79)$ & $8(32.00)$ & \\
\hline \multicolumn{4}{|l|}{ Marital status } \\
\hline Single & $5(6.58)$ & $12(48.00)$ & 0 \\
\hline Married & $68(89.47)$ & $12(48.00)$ & \\
\hline Separated & $3(3.95)$ & $1(4.00)$ & \\
\hline \multicolumn{4}{|l|}{ Religion } \\
\hline Christian & $44(57.89)$ & $14(56.00)$ & 0.868 \\
\hline Moslem & $32(42.11)$ & $11(44.00)$ & \\
\hline \multicolumn{4}{|l|}{ Occupation } \\
\hline Unemployed & $13(17.33)$ & $1(4.00)$ & \\
\hline Peasant & $35(46.67)$ & $3(12.00)$ & \\
\hline Business & $21(28.00)$ & $15(60.00)$ & 0.001 \\
\hline Professional & $6(8.00)$ & $6(24.00)$ & \\
\hline \multicolumn{4}{|l|}{ Income in Uganda shs } \\
\hline$<90,000 /=$ & $24(31.58)$ & $24(96.00)$ & 0 \\
\hline$>90,000 /=$ & $52(68.42)$ & $1(4.00)$ & \\
\hline
\end{tabular}

Table 2: Sexual and Reproductive Characteristics (N=101)

\begin{tabular}{|c|c|c|c|}
\hline Characteristic & $\begin{array}{c}\text { Controls } \\
\text { n (\%) } \\
\end{array}$ & $\begin{array}{l}\text { Cases } \\
\text { n (\%) }\end{array}$ & p-value \\
\hline \multicolumn{4}{|l|}{ Parity } \\
\hline 1 & $41(53.95)$ & $1(4.00)$ & \\
\hline 2 & $22(28.95)$ & $21(84.00)$ & 0 \\
\hline$>3$ & $13(17.11)$ & $3(12.00)$ & \\
\hline \multicolumn{4}{|l|}{ Menarche } \\
\hline$<12$ years & $2(2.67)$ & $1(4.00)$ & \\
\hline $12-14$ years & $37(49.33)$ & $21(84.00)$ & 0.006 \\
\hline$>14$ years & $36(48.00)$ & $3(12.00)$ & \\
\hline \multicolumn{4}{|l|}{ Coitarche } \\
\hline$<19$ years & $46(60.00)$ & $25(100.00)$ & 0 \\
\hline
\end{tabular}




\begin{tabular}{|c|c|c|c|}
\hline$>19$ years & $30(40.00)$ & $0(0.00)$ & \\
\hline \multicolumn{4}{|c|}{ Multiple sexual partners } \\
\hline No & & $11(44.00)$ & \\
\hline Yes & & $14(56.00)$ & 0.004 \\
\hline \multicolumn{4}{|c|}{ Induced abortion } \\
\hline None & $74(97.37)$ & $20(80.00)$ & \\
\hline 01-Apr & $2(2.63)$ & $5(20.00)$ & 0.003 \\
\hline \multicolumn{4}{|c|}{ History of previous PID } \\
\hline No & & $1(4.00)$ & \\
\hline Yes & & $24(96.00)$ & 0.002 \\
\hline \multicolumn{4}{|c|}{$\begin{array}{l}\text { History of puerperal } \\
\text { /postabortal sepsis }\end{array}$} \\
\hline No & $75(98.68)$ & $24(96.00)$ & \\
\hline Yes & $1(1.32)$ & $1(4.00)$ & 0.403 \\
\hline \multicolumn{4}{|c|}{ History of abdominal/pelvic surgery } \\
\hline No & & $12(48.00)$ & \\
\hline Yes & & $13(52.00)$ & 0 \\
\hline \multicolumn{4}{|c|}{ History of IUCD usage } \\
\hline No & $73(97.33)$ & $24(96.00)$ & \\
\hline Yes & $2(2.67)$ & $1(4.00)$ & 0.735 \\
\hline
\end{tabular}

Table 3: Factors associated with ectopic pregnancy at Multivariate Analysis.

\begin{tabular}{|c|c|c|c|c|}
\hline & Univariable & & Multivariable & \\
\hline Variable Chlamydia IgG Antibodies & OR[95\% CI] & $P$ value & $\mathrm{aOR}[95 \% \mathrm{CI}]$ & $P$ value \\
\hline No & 1 & 0.0019 & 1 & 0.0019 \\
\hline Yes & $4.4[1.70-11.48]$ & & $4.9[1.15-21.29]$ & \\
\hline \multicolumn{5}{|l|}{ Marital status } \\
\hline Single & $13.6[4.05-45.62]$ & 0 & $12.0[2.21-65.32]$ & 0.0026 \\
\hline Married & 1 & & 1 & \\
\hline Separated & $1.8[0.18-19.70]$ & & $0.6[0.04-8.48]$ & \\
\hline \multicolumn{5}{|l|}{ Parity } \\
\hline 1 & 1 & & 1 & \\
\hline 2 & $39.1[4.92-310.73]$ & & $24.9[1.47-205.98]$ & \\
\hline$>3$ & $9.4[0.90-98.96]$ & 0 & $6.9[1.47-32.98]$ & 0.3752 \\
\hline \multicolumn{5}{|l|}{ Menarche } \\
\hline$<12$ years & 1 & & 1 & \\
\hline 12-14 years & $1.1[0.09-13.27]$ & 0.0031 & $3.4[0.77-14.82]$ & 0.2796 \\
\hline$>14$ years & $0.1[0.01-2.41]$ & & $1.1[0.11-11.50]$ & \\
\hline \multicolumn{5}{|l|}{ Coitarche } \\
\hline$<19$ years & $0.6[0.02-0.34]$ & 0 & $0.9[0.37-2.28]$ & 0.8622 \\
\hline$>19$ years & 1 & & 1 & \\
\hline \multicolumn{5}{|l|}{ Multiple sexual partners } \\
\hline No & 1 & & 1 & \\
\hline Yes & $3.8[1.48-9.82]$ & 0.0051 & $3.1[0.18-11.88]$ & 0.4376 \\
\hline Induced abortion & & & & \\
\hline
\end{tabular}




\begin{tabular}{|c|c|c|c|c|}
\hline None & 1 & & 1 & \\
\hline 01-Apr & $9.2[1.66-51.27]$ & 0.0067 & $7.0[0.43-46.68]$ & 0.8681 \\
\hline $\begin{array}{l}\text { History of Abd } \\
\text { /pelvic surg }\end{array}$ & & & & \\
\hline No & 1 & & 1 & \\
\hline Yes & $12.6[4.02-39.71]$ & 0.0001 & $6.9[1.47-32.98]$ & 0 \\
\hline \multicolumn{5}{|c|}{ History of previous PID } \\
\hline No & 1 & & 1 & \\
\hline Yes & $104[24.23-171.5]$ & & $85[33.14-169.4]$ & 0.5689 \\
\hline
\end{tabular}

\section{Discussion}

Our study found that women with ectopic pregnancy were more likely to be single, corroborating the findings in another Nigerian study [24]. This can be explained by the fact that single women are more likely to have multiple sexual partners than married women. In examining the risk factors for Chlamydia infection among patients with ectopic pregnancy and normal pregnancy this study looked at the sexual and reproductive characteristics of both groups. The results of univariate analysis showed that women with ectopic pregnancy engaged in sexual intercourse at a significantly younger age than women with intra uterine pregnancy. This finding is in keeping with previous studies which linked early coitarche with Chlamydia trachomatis infection [8]. Adolescents are prone to sexually transmitted disease (STD) because of high risk sexual behaviour. Biologically, the adolescent is particularly at risk of STD because the columnar epithelium, which is susceptible to Chlamydia and gonococcal organisms extend from the endocervical canal to the ectocervix making it fully exposed to pathogens. They also have difficulties using barrier methods of contraception and may have less access to STD care because of limited facilities, negative peer pressure, concealment and restrictive policies especially in the developing countries [9]. Previous history of pelvic inflammatory disease was significantly higher in patients with ectopic pregnancy when compared with women with normal pregnant controls. This agrees with the findings of previous studies in this regard [25].

In contrast to other studies [25], this study found that induced abortions were relatively low in women with ectopic pregnancy and did not have any association with ectopic pregnancy. This could be explained by the small number of participants in this study who had a history of induced abortions and therefore it was difficult to assess statistical difference with such a small number. In our study previous history of abdominal/ pelvic surgery was associated with ectopic pregnancy and this compares with studies done in other areas [15].This could be explained by the fact that previous surgery in the pelvic area or on the tubes can cause adhesions and impede the egg's movement causing implantation in the tubes and other sites. However, when these were subjected to logistic regression model (multivariate) analysis, patients with Chlamydia antibodies showed a four-fold increase in the risk of ectopic pregnancy when controlling for previous history of pelvic inflammatory disease. In addition, the multivariate analysis revealed that women with history of previous abdominal/pelvic surgery and those that were single were significantly associated with ectopic pregnancy.

\section{Conclusion}

This study has shown that being single and having a history of previous abdominal/pelvic surgery were positively associated with ectopic pregnancy. Furthermore, a greater proportion of women with ectopic pregnancy had serological evidence of prior C. trachomatis infection than women with intrauterine pregnancy. It also demonstrated a four-fold risk association between prior $C$. trachomatis infection and ectopic pregnancy.

\section{Acknowledgement}

We thank all the participants and the staff of the department of obstetrics and gynecology of MRRH and the staff of lancet laboratories for their unwavering support during this study. Special thanks also go to my father for the financial support.

\section{References}

1. Dabota BY (2011) Management and outcome of ectopic pregnancy in developing countries. Ectopic Pregnancy-Modern Diagnosis and Management. InTech.

2. Rajkhowa M, Glass MR, Rutherford AJ, Balen AH, Sharma V, et al. (2000) Trends in the incidence of ectopic pregnancy in England and Wales from 1966 to 1996. BJOG: An International Journal of Obstetrics \& Gynaecology 107(3): 369-374.

3. Abbott L (2004) Ectopic pregnancy: Symptoms, diagnosis and management. Nursing times 100: 32.

4. Rotas MA, Haberman S, Levgur M (2006) Caesarean scar ectopic pregnancies: etiology, diagnosis, and management. Obstet Gynecol 107(6): 1373-1381

5. Barnhart KT, Gracia CR, Reindl B, Wheeler JE (2003) Usefulness of pipelle endometrial biopsy in the diagnosis of women at risk for ectopic pregnancy. Am J Obstet Gynecol 188(4): 906-909.

6. Thonneau P, Hijazi Y, Goyaux N, Calvez T, Keita N (2002) Ectopic pregnancy in Conakry, Guinea. Bull World Health Organ 80(5): 365-370.

7. Amoko DH, Buga GA (1995) Clinical presentation of ectopic pregnancy in Transkei, South Africa. East Afr Med J 72(12): 770-773.

8. Maccato M, Estrada R, Hammill H, Faro S (1992) Prevalence of active Chlamydia trachomatis infection at the time of exploratory laparotomy for ectopic pregnancy. Obstet Gynecol 79(2): 211-213.

9. Coste J, Bouyer J, Ughetto S, Gerbaud L, Fernandez H, et al. (2004) Ectopic pregnancy is again on the increase. Recent trends in the incidence of ectopic pregnancies in France (1992-2002). Hum Reprod 19(9): 20142018.

10. Egger M, Low N, Smith GD, Lindblom B, Herrmann B (1998) Screening for chlamydial infections and the risk of ectopic pregnancy in a county in Sweden: ecological analysis. BMJ 316(7147): 1776-1780. 
11. Gottlieb SL, Brunham RC, Byrne GI, Martin DH, Xu F, et al. (2010) Introduction: the natural history and immunobiology of Chlamydia trachomatis genital infection and implications for chlamydia control. Infect Dis 201(suppl 2): S85-S87.

12. Trelle S, Shang A, Nartey L, Cassell JA, Low N (2007) Improved effectiveness of partner notification for patients with sexually transmitted infections: systematic review. BMJ 334(7589): 354.

13. Rekart ML, Brunham RC (2008) Debate. Epidemiology of chlamydial infection: Are we losing ground? Sex Transm Infect 84(2): 87-91.

14. Organization WH (2013) Global and regional estimates of violence against women: prevalence and health effects of intimate partner violence and non-partner sexual violence, World Health Organization, Geneva, Switzerland.

15. Organization WH, HIV/AIDS, UNPO (2010) Towards universal access: scaling up priority HIV/AIDS interventions in the health sector. Progress report, 2010. Towards universal access: scaling up priority HIV/AIDS interventions in the health sector. Progress report.

16. Barnhart KT, Sammel MD, Gracia CR, Chittams J, Hummel AC, et al. (2006) Risk factors for ectopic pregnancy in women with symptomatic first-trimester pregnancies. Fertil Steril 86(1): 36-43.

17. Skjeldestad F, Hadgu A, Eriksson N (1998) Epidemiology of repeat ectopic pregnancy: a population-based prospective cohort study. ObstetGynecol 91(1): 129-135.

18. Michalas S, Minaretzis D, Tsionou C, Maos G, Kioses E, et al. (1992) Pelvic surgery, reproductive factors and risk of ectopic pregnancy: a case controlled study. Int J Gynecol Obstet 38(2): 101-105.
19. Riveles K, Roza R, Arey J, Talbot P (2004) Pyrazine derivatives in cigarette smoke inhibit hamster oviductal functioning. Reprod Biol Endocrinol 2: 23.

20. Kamwendo F, Forslin L, Bodin L, Danielsson D (2000) Epidemiology of ectopic pregnancy during a 28 year period and the role of pelvic inflammatory disease. Sex Transm Infect 76(1): 28-32.

21. Marchbanks PA, Annegers JF, Coulam CB, Strathy JH, Kurland LT (1988) Risk factors for ectopic pregnancy: a population-based study. JAMA 259(12): 1823-1827.

22. Rosado F (2014) Factors associated with chlamydia trachomatis reinfection among puerto rican adolescents 2008-2012.

23. Bouyer J, Coste J, Shojaei T, Pouly JL, Fernandez H, et al. (2003) Risk factors for ectopic pregnancy: A comprehensive analysis based on a large case-control, population-based study in France. Am J Epidemiol 157(3): 185-194

24. Musa J, Daru P, Mutihir J, Ujah IA (2008) Ectopic pregnancy in Jos Northern Nigeria: prevalence and impact on subsequent fertility. Nigerian J Med 18(1): 35-38.

25. Den Hartog JE, Land JA, Stassen FR, Slobbe Van Drunen ME, Kessels AG, et al. (2004) The role of chlamydia genus-specific and species-specific IgG antibody testing in predicting tubal disease in subfertile women. Hum Reprod 19(6): 1380-1384.

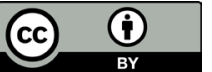

Creative Commons Attribution 4.0 International License

For possible submissions Click Here

\section{Submit Article}

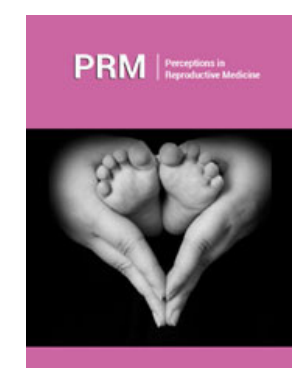

Perceptions in Reproductive Medicine

\section{Benefits of Publishing with us}

- High-level peer review and editorial services

- Freely accessible online immediately upon publication

- Authors retain the copyright to their work

- Licensing it under a Creative Commons license

- Visibility through different online platforms 